Article

\title{
Interdisciplinary Service Design Approach to Promote Sustainable Solutions in Social Complexity: Case Study on Korean Elderly Residential Stability during COVID-19
}

\author{
Suji Choi ${ }^{1}\left(\right.$, Miseon Kang ${ }^{2}$,, Yeseul Lee ${ }^{2}$, Seol-Ah Lee ${ }^{2}$, Hyoun K. Kim ${ }^{2}$ and Hyun-Kyung Lee ${ }^{3, *(1)}$ \\ 1 Department of Human Environment and Design/Human Life Innovation Design, Yonsei University, \\ Seoul 03722, Korea; charcalling@yonsei.ac.kr \\ 2 Department of Child and Family Studies/Human Life Innovation Design, Yonsei University, \\ Seoul 03722, Korea; ejrwolfdyd@yonsei.ac.kr (M.K.); yslee0822@yonsei.ac.kr (Y.L.); \\ 1026lsa@yonsei.ac.kr (S.-A.L.); hyounkim@yonsei.ac.kr (H.K.K.) \\ 3 Division of Culture \& Design Management, Underwood International College, Yonsei University, \\ Seoul 03722, Korea \\ * Correspondence: hyunkyunglee@yonsei.ac.kr
}

check for updates

Citation: Choi, S.; Kang, M.; Lee, Y.; Lee, S.-A.; Kim, H.K.; Lee, H.-K. Interdisciplinary Service Design Approach to Promote Sustainable Solutions in Social Complexity: Case Study on Korean Elderly Residential Stability during COVID-19. Appl. Sci. 2021, 11, 12009. https://doi.org/ 10.3390/app112412009

Academic Editor: Byung Yung Jeong

Received: 15 October 2021

Accepted: 14 December 2021

Published: 16 December 2021

Publisher's Note: MDPI stays neutral with regard to jurisdictional claims in published maps and institutional affiliations.

Copyright: (c) 2021 by the authors. Licensee MDPI, Basel, Switzerland. This article is an open access article distributed under the terms and conditions of the Creative Commons Attribution (CC BY) license (https:/ / creativecommons.org/licenses/by/ $4.0 /)$.

\begin{abstract}
This study introduces Action Research to present a service program through an interdisciplinary service design approach for promoting the residential stability of elderly people. We extracted design elements (1) "things to do" and (2) "community" and "strategies", and then made a design framework. According to the framework, we developed a service design program, named "Small Daily Life: "Small Daily Life Tasks", which provided opportunities to share the elderly people's daily life via online videos "Small Meeting", which helped develop a network of relationships outside the home by informing neighbors regarding elderly people's know-how, and "Small Sharing", which delivers the results of previous activities to those who need help in the community. Finally, we describe our reflective case study on the presented service program and examine the relationship between social infrastructure and design and their respective roles. This study will expand service design methodologies as presented research procedures, generalized frameworks, and conceptual models that can be referenced in multidisciplinary collaborations.
\end{abstract}

Keywords: service design; interdisciplinary approach; social complexity; social innovation; residential stability

\section{Introduction}

The world is aging. According to [1], one-sixth of the global population will be over 60 years old by 2030. Additionally, South Korea, which is one of the rapidly aging countries, is predicted to be the oldest country in the world in 2045 [2]. Among social issues caused by the aging phenomenon, Korean governments have put efforts into finding better answers to solve housing problems. Nursing homes, named as long-term care facilities in South Korea, have strengths in prompt medical treatment, but there is a possibility to provoke unwanted moving or social isolation.

"Home" is a space where people feel stable and comfortable, which plays an essential role in one's emotional well-being [3]. According to [4], for the elderly, "residence" is a place where social interactions occur through contact with neighbours and local communities. As a result, the direction to solve housing problems of older adults has moved to pursue an "Aging in place", which means to continue living in the community where they have lived, rather than institutionalization [5]. Therefore, continuing community life in old age can facilitate the maintenance of psychological and emotional health and further alleviate physical frailty in the elderly [6].

Based on the background above, this study will conduct Action Research [7] to present service programs to improve older adults' residential stability through an interdisciplinary 
service design approach. Service design is "the design of activities and organized services" [8] (p. 232) and the methodology that provides innovative "experiential value" to service users by contextually identifying the various elements that make up the service and experience, capturing latent needs between stakeholders and visualizing them in a creative and collaborative way $[9,10]$. The design issues addressed by the service design are not only simple problems, but also "wicked" [8], which are not visible, and the methods for resolving these are not well known and involve various stakeholders [11]. In this sense, improving the residential stability of older adults is intricate enough to be a theme of service design research, because it relates to various aspects such as the physical decline of older adults, social connection in community, and so on. In addition, this study was conducted by academic convergence. As interdisciplinary teamwork enables researchers to apply multi-faceted perspectives and information on the study, it is also helpful to design service programs dealing with complex social problems such as the residential stability of older adults, which is the main theme of this study.

The remainder of this paper is organized as follows. (1) We describe the status and theoretical background of the residential stability issues of older people, which are concrete contexts for this study. (2) We systemize the research process for an interdisciplinary approach. (3) Based on the research process we developed, we extract design elements and strategies for solving the residential stability of older adults and present our own service program. (4) We describe our reflective case study of the presented service program and examine the relationship between social infrastructure and design, and their respective roles. The last step is to present a conceptual model that can broadly affect various studies and national policies, in addition to the design field. The research questions are as follows:

Research question 1. What 'design element' provides the best experience in our developed services?

Research question 2. What 'design strategy' provides the best experience in our developed services?

Research question 3. What is the role of social infrastructure and design field in "social" service development for resolving residential welfare issues?

\section{Methods}

This study is an interdisciplinary service design study conducted in collaboration with design experts, children, and family studies experts who specifically majored in gerontology. The study systematized the research process for an interdisciplinary approach to effectively integrate knowledge of two areas while following the fundamental processes of service design such as "Double Diamond" (which as of 2015, Design Council presented on its website) through Discover-Define-Develop-Deliver [12]. This study is preceded by "Deriving the design framework", which is a process of extracting optimal design elements and strategies through collaboration between two different areas and creating a design "frame" [13]. According to [13], creating a "frame" defines the "working principle" of "WHAT" to create, focusing on the "value" to derive- "The elderly numerical stability", for this study. Neither the problem nor the solution is fixed; hence, the process of matching between two spaces allows creative design [14]. In this study, experts from two fields conducted an analysis of literature, prior service cases, various statistics, and two stakeholder interviews, and extracted design elements and strategies to derive the final design framework. In this process, collaborative research cooperated creatively through 'expert meeting' three times rather than performing separate roles. In the meeting, they provided each other with the background knowledge and skills they had. Four researchers from gerontology provided background knowledge about qualitative coding and ecosystem theory enabling to extend the concept of residential experience to interactions with the surrounding environment [15], while two researchers in the design field provided knowledge about data visualization and branding methodology.

The collaborative research team introduced Action Research to develop and reflect the service program from the perspective of the elderly. Action Research is a research 
methodology originally used in pedagogy, and researchers participate in their own exploration while practicing as both a class designer and an experience to better understand the learning context [7]. In this study, Action Research is conducted by designing a service program and participating in the program as a case. We examined the elderly's experiences in detail within that context.

In this study, two semi-structured interviews were conducted for service design. The two interviews are based on qualitative research targeting two elderly people in the first case and five elderly people in the second case. Despite the apparent limitations of a small sample size, it can provide reliable indications for the directions in which future research can go [16]. In the context of this study, two important interviews guided the service's design direction in the process of extracting design elements and establishing design strategies. Listening to interviewees' stories while interacting for a long time is a kind of 'narrative research' that is effective in understanding the context of the subject's life and can provide important insights in design by understanding the subject's life in three dimensions [17]. For example, Orth and fellow researchers designed objects through the three individuals' narratives [18].

The first interview was an exploratory process for the extraction of design elements, and was conducted on the elderly, who are the core targets of the service. At this stage, in order to deeply understand the residential life of the elderly, we had a long conversation with two elderly people in their 70s and 80s. The age groups of the two elderly were different, and whether they lived together was also different. In the case of elderly 1 in their 80 s with a roommate, the roommate was also included in the interviewee. In the service development stage, in addition to the core subjects, the stakeholders were also considered. The questions consisted of general questions such as overall thoughts about 'home', inconveniences in residential life, comfort/safety, COVID-19, and recent concerns.

The second interview was conducted to establish a specific strategy. Five people were targeted, and one care worker was included to objectively grasp the residential life of four elderly people and the elderly living in facilities. In the case of the second interview, in order to understand the lives of the elderly, focusing on the design elements derived through the first interview analysis, daily routine, self-efficacy, and life reward were asked.

In accordance with guidelines for data analysis in qualitative and Action Research [19], data analysis was largely structured into two stages: Open Coding and Axial Coding. In the first step, (1) basic information (Age, Gender, Residence, Family Member) is identified, and (2) the code is identified based on the basic information. Additionally, (3) in special cases, codes are categorized in consideration of basic information and context. The second step is to visualize the categories from above by axial coding. All of these processes involved six professional researchers.

In this study, a total of two interviews were conducted according to the following consent procedure. (1) The research participant recruitment process distributed research participant recruitment documents, research participation consent forms, interview participant recruitment documents, and interview participation agreements and (2) explained the purpose and contents of the study in detail, and voluntarily participated in the study and interview.

We implemented a service concept design, branding, and service process design based on the derived service design framework. Branding adds a dimension to products that can help it in being differentiated from other products that satisfy the same needs, thereby stimulating positive public support $[20,21]$. In this study, branding was included in the service design development process for the social ripple effects of the services we intend to develop. The presented service program takes the form of a 'process' and is presented as "service blueprint", one of the main visualization methods of service design. Finally, we presented cases and analysed them reflectively to derive a conceptual model that could inform efforts for the development and research of service design to improve the residential stability of the elderly. A summary of the above process is presented in Figure 1. 


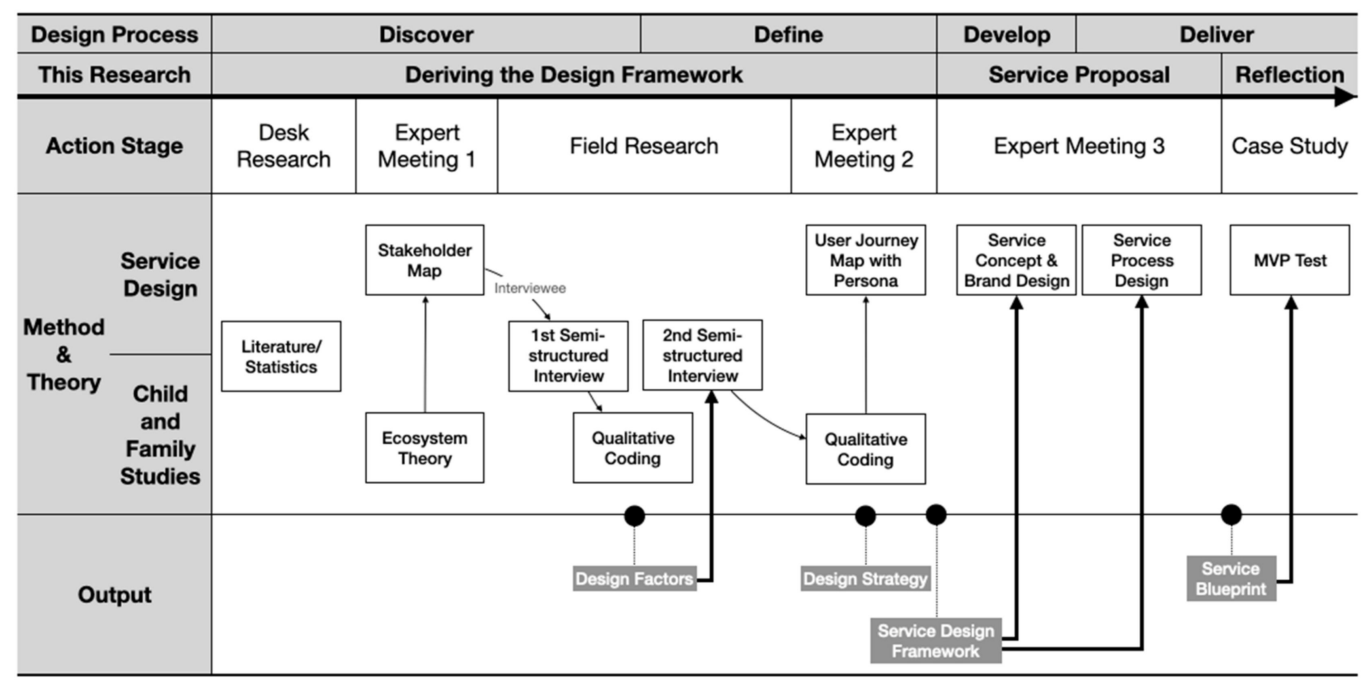

Figure 1. Interdisciplinary approach of research process.

\section{Results}

\subsection{Deriving the Design Framework}

\subsubsection{Derivation of Design Elements}

Pre-interviews and case studies were conducted to derive design elements. After receiving consent, the researcher visited interviewees' homes on 15 and 18 April 2020 for an hour for face-to-face interviews. The interview questions consisted of the perception of the house, experiences in the house, and the function of the house. All interviews were recorded on a smartphone recorder and transcribed. Four researchers analysed the transcribed data.

Two elderly women and one adult child were interviewed. Senior 1 was living with her son, who also participated as an interviewee. She moved into the current house with her son five years ago, which is not so far from her formal residence. Senior 2 has lived in the home for the past 30 years, and she is living alone after the passing of her husband a year ago. The characteristics of the first interviewees are listed in Table 1.

Table 1. Characteristics of first interviewees.

\begin{tabular}{cccccc}
\hline Order & Subject & Age & Gender & $\begin{array}{c}\text { Residence Type/ } \\
\text { Working Facility }\end{array}$ & $\begin{array}{c}\text { Cohabitating } \\
\text { Family Members/ } \\
\text { Special Matters }\end{array}$ \\
\hline- & $\begin{array}{c}\text { Senior 1 } \\
\text { Senior 2 } \\
\text { Adult child } \\
\text { of Senior 1 }\end{array}$ & 86 & Female & $\begin{array}{c}\text { Apartment } \\
\text { Apartment }\end{array}$ & $\begin{array}{c}\text { One adult child } \\
\text { Living alone } \\
\text { One elderly mother } \\
\text { (Senior 1) }\end{array}$ \\
\hline
\end{tabular}

In the interview, the elderly participants reported various reasons for being socially disconnected, depending on their age. During the interview, Senior 1 (86 years old, female) reported high levels of social disconnection due to changes in her physical ability. Even if she attended the senior day care centre, she only participated in the given activities and did not have much social exchange beyond the activities. Her adult child (50 years old, male) mentioned his mother's need for assistance in her daily life, which again identified the disconnection caused by the physical changes that occur in the super-aged. Senior 2 (76 years old, female) experienced reduced social exchanges after her husband entered a facility and voluntarily cut off her interactions with others. Further, she indicated psychological changes by revealing her fears about living alone in the future due to her social disconnection experiences. She also perceived her home as her own space, where 
her family often visited. As such, the two older adults demonstrated differences in their physical abilities and psychological changes due to social disconnection. However, they shared a similar desire to engage in social interactions and recognize that the home is a caring and living space for their family to visit. They also reported that their loneliness had deepened as the COVID-19 pandemic increased the amount of time they spent at home.

The first interviews showed that sincere social relationships and productive experience through role performance were common desires of elderly interviewees Figure 2. Their perception of a home was a private space where they lived and where their children and families visited. This suggests the need to form support communities outside private spaces. Therefore, this study first derived design elements such as "things to do" and "community".

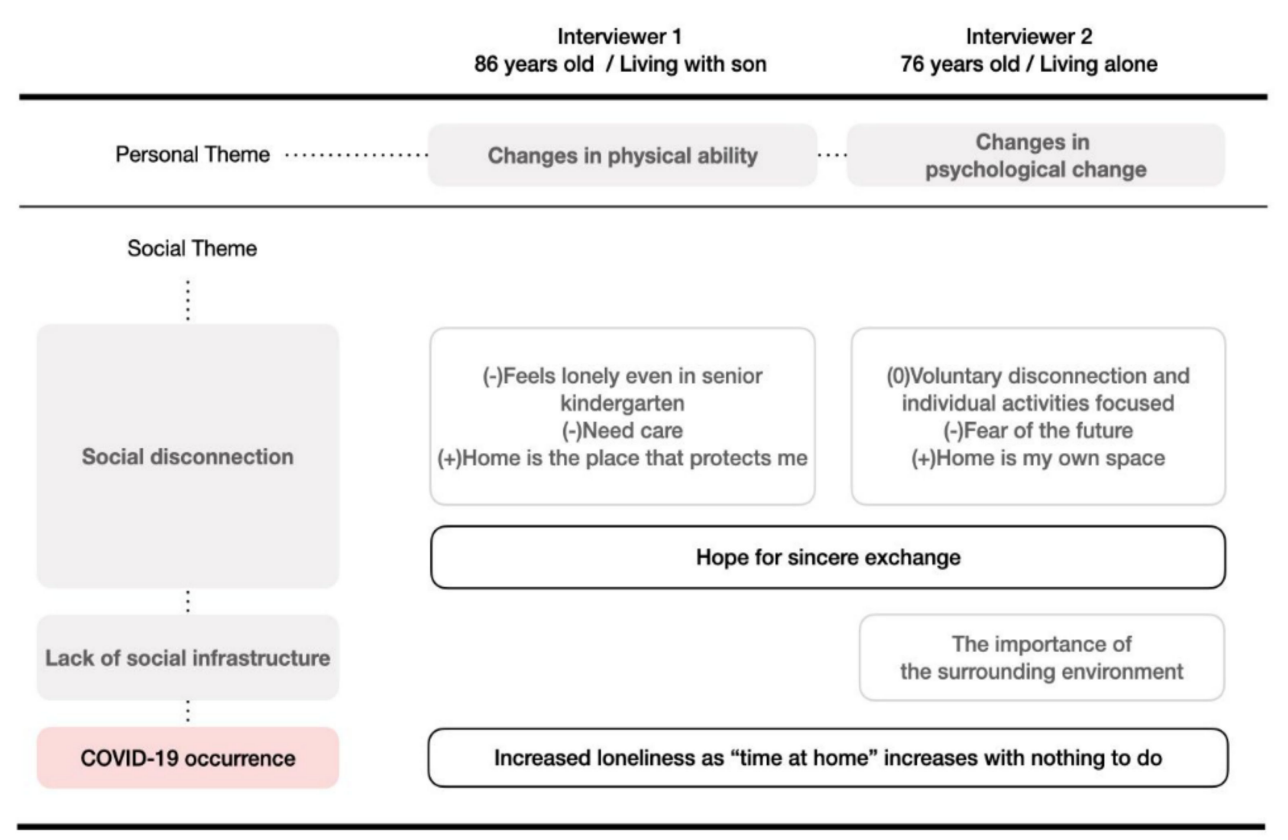

Figure 2. First interview's outcomes and derived design elements.

Next, we examined several housing projects and elderly community activity cases to promote social exchanges at home and abroad. First, the Japanese government implemented the "Smart Wellness Housing Promotion Project" and established social welfare facilities for residents in public housing complexes targeting the elderly. This project was linked to housing policy and welfare policy and promoted social exchange and relationships among the elderly [22]. Germany has also established a multi-generational exchange centre called the "Mehr generationen haus". The centre provides a federally funded program to ease social isolation issues among the elderly and the disconnection between generations. There are approximately 550 such houses distributed throughout Germany, where various generations gather to interact through volunteer work and joint activities [23].

An example of a popular offline and community activity in Korea is "Book-Reading". It creates jobs for the elderly and encourages that their social activities are carried out through community welfare facilities. Since 2016, Songjeong Village in Buyeo has collected paintings from the senior citizens' centre and has held two exhibitions and published a book of fairy tales. Since then, a "picture book village" has been created, and book reading activities are provided for visitors in the "picture book village tea house", a community space in the village.

Seoul City's bean paste-making project is also a successful example of offline community activities. Since 2017, food education experts and residents have shared a pot and bean paste-making process to achieve a great response. In 2020, 20 districts installed "Seoul Jangdokdae", in which a community space created and stored traditional Korean pastes. 
However, these offline community activities were limited, as it is difficult for the elderly with limited mobility to participate.

Online platforms are a community space where even elderly adults with reduced mobility can engage in social exchanges. An example of senior activities on an online platform is "Park Makrye, Korean Grandma". This YouTube channel consists of multi-generational collaboration activities within the family, featuring the grandmother's content and granddaughter's planning and editing. There are also autonomous sensory meridian response (ASMR) videos featuring the everyday lives of rural grandmothers such as "Soonja's Mom" and "Cauldron Hipsters", and include cooking-based content from grandmothers.

The following cases are good examples of community-based social participation programs for elderly adults in the United States: "Catch Healthy Habits", in which seniors taught children healthy eating and physical activity habits; "Family Friends", in which seniors visit local isolated children or families to act as caregivers and mentors; and "Grandfather Reading Buddies", in which retired servicemen and policemen helped local five- to nine-year-old boys of colour. These cases allowed elderly people to experience a sense of productivity through "things to do", but they also helped community members and met the needs of social exchange.

However, these programs were based on professional relationships with corporations or generational collaborations within the family. This made it difficult to apply many of these programs to ordinary elderly adults. There was also the limitation that by focusing on activities outside the home, they still separated the private space from the local community rather than extending the living space into the elderly's local community. Based on this analysis, this study was able to derive the need for a service that provided elderly people with self-efficacy and forms of social relationships by sharing the "everyday life" activities in and out of the home. Moreover, program activities that extended sequentially to individuals, neighbours, and communities via online and offline platforms were expected to lower the barriers for elderly adults to enter the service.

\subsubsection{Establishing a Design Strategy}

To establish a specific design strategy, in-depth interviews were conducted based on the collected design elements. A daily life journey map for female seniors was developed according to the content of the in-depth interviews.

The in-depth interview questions focused on daily life, loneliness, and activities or contents that they found rewarding. Five people individually participated in in-depth interviews, and Table 2 lists the subjects discussed. The interviewees in this round also provided prior consent for participation, and a telephonic interview was conducted if a face-to-face interview could not be arranged due to COVID-19. Accordingly, two face-toface interviews were conducted with elderly adults on 25 April and 2 May 2020, and one face-to-face interview was conducted with a care worker on 29 April. Two other interviews were conducted via telephone. All the recorded files were transcribed and documented. Four researchers analysed transcribed data.

Table 2. Characteristics of second interviewees.

\begin{tabular}{|c|c|c|c|c|c|}
\hline Order & Subject & Age & Gender & $\begin{array}{l}\text { Residence Type/ } \\
\text { Working Facility }\end{array}$ & $\begin{array}{c}\text { Cohabitating Family } \\
\text { Members/ } \\
\text { Special Matters }\end{array}$ \\
\hline- & Senior 1 & 86 & Female & Apartment & One adult child \\
\hline- & Senior 2 & 89 & Female & Nursing hospital & $\begin{array}{l}\text { One adult child, visits two to } \\
\text { three times a month }\end{array}$ \\
\hline- & Senior 3 & 76 & Female & A single house & Living alone \\
\hline- & Senior 4 & 75 & Female & Apartment & Living alone \\
\hline- & Care worker & 66 & Male & Nursing hospital & $\begin{array}{l}\text { Nine months of work at a } \\
\text { medium-sized nursing hospital }\end{array}$ \\
\hline
\end{tabular}


Senior 1 (86 years old, female) agreed to have her daily life filmed and shared with others. She also said that she wanted to share a video of her singing with others, as she enjoyed singing. Senior 2 (89 years old, female) was greatly discouraged by having nothing to do while living in a nursing home recovering from a fall. Further, throughout the interview, she mentioned that if she recovers and returns home, she wishes to cook for her children in her kitchen as before. Even though Senior 3 (76 years old, female) mentioned her experience of reading books to the elderly in the elderly welfare centre, she said that the grandmothers who appear on video service platforms (e.g., YouTube) are "smarter" than her. She also mentioned that she could do well with her own experience if she created the content of reading books to people. Meanwhile, Senior 4 (75 years old, female) showed the physical and psychological burden of participating in service contents such as reading fairy tale books due to the physical changes she had experienced. However, she talked about "growing plants", her hobby, which she felt rewarded her while she was at home, and she delighted in talking about the flowerpots that were in full bloom at the time of the interview. A nursing care worker (66 years old, male) shared the experiences of the elderly in the nursing hospital. Further, he said that they formed a bond with other elderly people through "song", mentioning that these moments gave the elderly a sense of stability in their living environment as well as enjoyment. The elderly in welfare centres usually spend the daytime participating in recreational activities such as dance, magic, and singing. However, all programs were suspended due to the COVID-19 pandemic.

Through interviews with the elderly living in a nursing hospital and a care worker, it was identified that the elderly's residence style and ability to perform daily life activities varied depending on whether they lived in the community or the facilities. The fact that they had a low chance of interacting with other elderly adults in the facility due to COVID19 also affected them. Based on these findings, we narrowed down our service targets to older adults living in the community.

To establish a design strategy and subsequent processing, our research team, one member majoring in life design, and three members majoring in family and gerontology created a customer journey map based on the elements derived from the in-depth interview Figure 3. This map allowed us to check not only the daily activities of female seniors from wake-up to bedtime, but also emotional changes according to activities and circumstances. They reported negative feelings when they felt socially disconnected and lethargic. Conversely, they experienced positive feelings when they found joy in daily activities such as "caring for a flowerpot" (i.e., gardening) and social interactions.

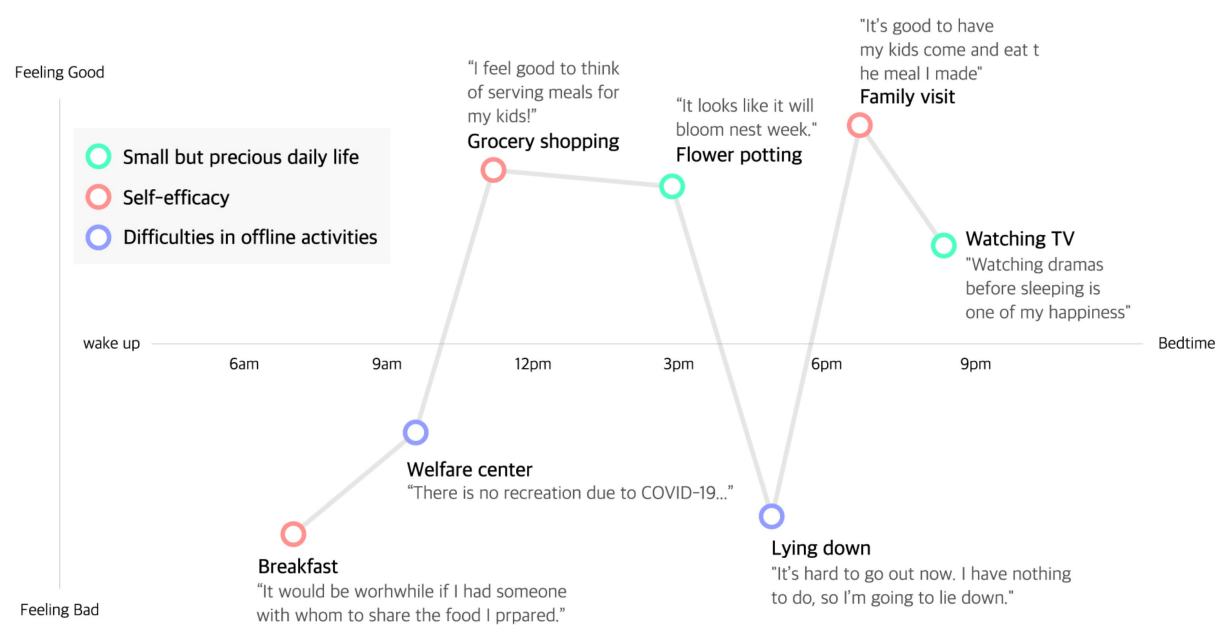

Figure 3. Customer journey map showing daily life of elderly female during second interview.

The daily life journey map and subsequent design strategies were triangulated through in-depth interviews and feedback from one life design expert and one child and family 
science expert. So, it was identified that the "things to do" should focus on elderly people sharing their actual hobbies and daily lives. Therefore, as a design strategy, we set up a "residence-linked social network service" to share trivial things and promote communication between generations by reducing barriers to accessing the easy-to-access content for the elderly. To this end, the flexibility of community space was considered online and offline, allowing the elderly to engage in activities both inside and outside the house, and by expanding the choice of place for activities according to their social conditions and personal circumstances. The resulting design strategy is as follows:

Design strategy 1 . It is possible to share a pleasant everyday task during their daily routine.

Design strategy 2. Promote self-efficacy by exhibiting talent through small things.

Design strategy 3. Expand community networks by combining online and offline activities.

The specific purpose and content of each design strategy are as follows: the first design strategy was to design a service with a low barrier so that female seniors could participate more easily by sharing the content of their daily lives that they already enjoyed. When asked about their participation in reading fairy tales, the elderly demonstrated a passive attitude by discussing the difficulty they had reading due to aging. Meanwhile, the elderly were found to experience positive feelings when conducting small daily tasks such as growing plants, watching TV, and singing.

Strategy 2 aims to reduce the boredom and lethargy of female seniors through productive activities and promote self-efficacy by providing new roles. The elderly interviewed all derived a great deal of delight and meaning from their children and grandchildren's visits. Accordingly, the service was designed to focus on enjoyable activities, such as cooking for family and neighbours.

Last, Strategy 3 was established to provide elderly women a multi-faceted field for community networks by allowing spaces to share daily life activities, pass on their talents, and share activities from both inside and outside their homes. Planning activities within the residential space enabled service proposals that were not limited to situations where external activities were restricted due to social problems such as the COVID-19 pandemic or the physical aging of the elderly. Additionally, once the COVID-19 pandemic's effects stabilize, this strategy could be expanded to offline activities, motivating the elderly to go out and encourage face-to-face social exchange and communication.

Based on the conceptual framework of the "expansion of residence concept", Figure 4 shows the service design framework that embodies design elements and strategies for improving the residential stability of the elderly.

\subsection{Service Proposals}

\subsubsection{Service Concept and Brand Design}

The specific service contents according to the derived design strategies were divided into three categories: (1) activities inside the home of female seniors by sharing aspects of daily life; (2) activities outside the home where they share talents, such as cooking and living know-how; and (3) community activities that share the results created through sharing of their daily life activities and talents. The main point encompassing the three service concepts was the service scope and the unit of activity for the elderly. Starting from the familiar space and contents of daily life, it leads to a meeting outside the house, where self-efficacy is cultivated through role contribution in the community space and where real conversations occur. These meetings can then lead to community activities through future sharing. The service provision was intended to share daily life in the house online while donating their talents and community sharing activities outside the house offline. Online channels for sharing daily life and offline bulletin boards were used to promote these activities. Table 3 summarizes the contents and provisions of the above service. 


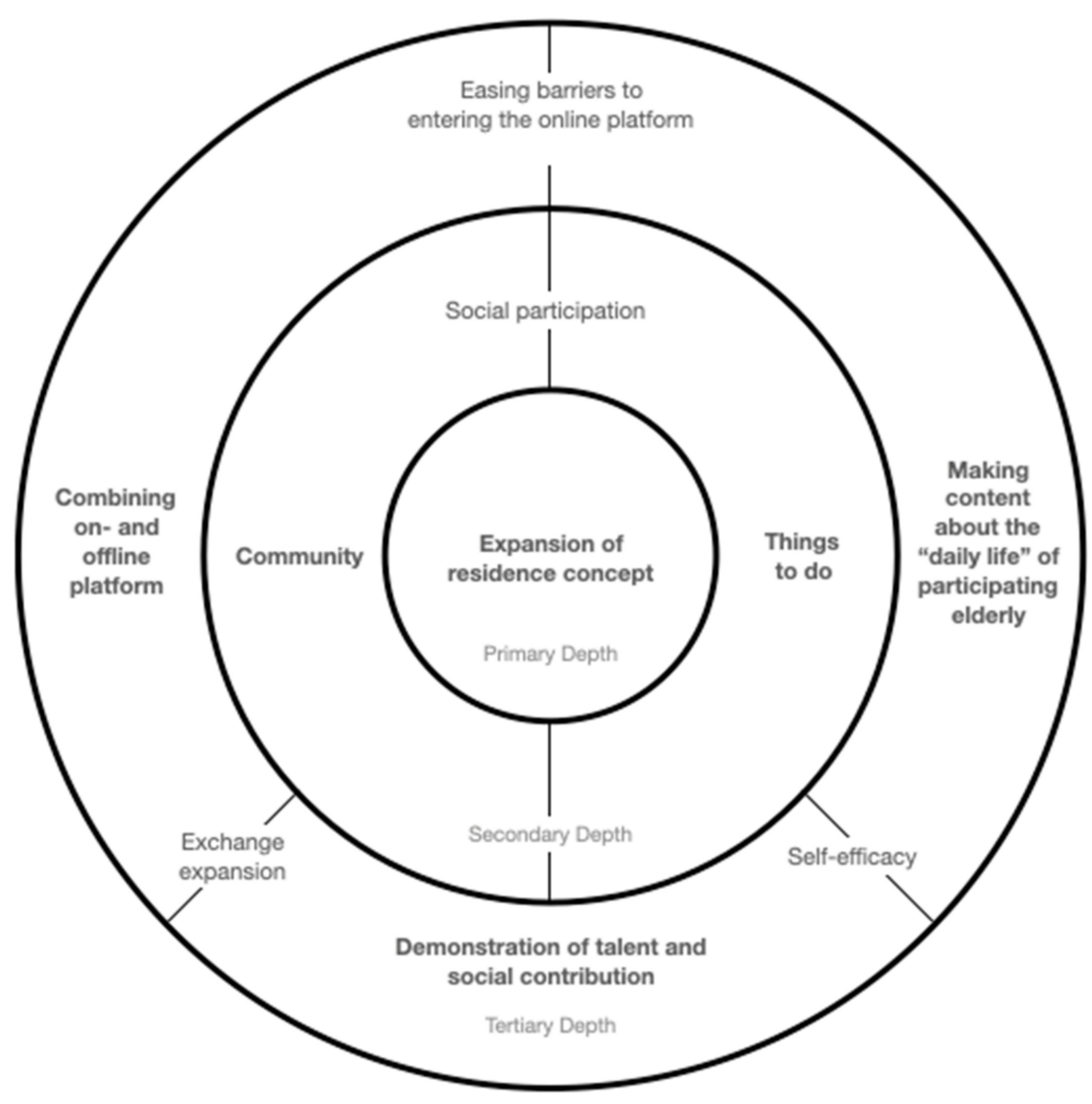

Figure 4. Service design framework.

Table 3. Contents and provision method of service.

\begin{tabular}{cccc}
\hline Service Unit & Main Content & $\begin{array}{c}\text { Service } \\
\text { Provision Method }\end{array}$ & Note \\
\hline $\begin{array}{c}\text { Activities inside } \\
\text { home } \\
\begin{array}{c}\text { Activities outside } \\
\text { home }\end{array}\end{array}$ & Sharing daily life & Online & $\begin{array}{c}\text { Combined promoting } \\
\text { by on- and offline }\end{array}$ \\
Community activities & $\begin{array}{c}\text { Sharing the results } \\
\text { created through daily } \\
\text { life and talent donation }\end{array}$ & Offline & - \\
\hline
\end{tabular}

To visually represent this service, the brand name "Small Daily Life" was designed under the concept of "Highlights of grandma's small daily life activities" Figure 5. A short brand name was selected to focus on sharing the small tasks of daily life and enjoyment of the elderly, improving the delivery of meaning and accessibility of the service to the elderly who would become service users. The yellow underline behind "Small Daily Life" encapsulates the meaning of the service to "highlight small daily life" that emphasizes the daily lives of the female elderly.

\subsubsection{Service Proposal}

The service "Small Daily Life" proposes three service elements according to the following concepts to improve the residential stability of the female elderly.

Grandma's "Small Daily Life Tasks": A service for sharing small hobbies of Grandma at home through video. 
Grandma's "Small Meeting": A time for grandmothers and neighbours to work together and learn cooking and living know-how.

Grandma's "Small Sharing": Sharing the results of small daily life tasks and small meetings in the local community.

"Grandma's Small Daily Life Tasks" is an online service that shares the small daily life tasks in which elderly women take pleasure at home in a short video diary format. The elderly can record their daily routines, strengthening their perception of the joyful emotions they feel in everyday activities by re-viewing them. Additionally, by sharing the video online, it is possible to feel the relational contact even at home through interaction with children who live apart, with family members, or others who provide feedback on their content.

"Grandma's Small Meeting" is a small group activity for a region in which neighbours join elderly women to learn cooking skills and living know-how. This service initiates, maintains, and contributes to the elderly community network by creating an environment in which they can contribute to the role of teaching previously known and/or familiar skills and enabling communication with neighbours, particularly across generations.

"Grandma's Small Sharing" is an activity for sharing the food and handicrafts made by the elderly women in the "Small Daily life Tasks" and "small meetings". It expands social community contributions and networking through interpersonal activities outside the home. The goal of this service is the "enhancement of residential stability" of the elderly, developed independently, through meetings with small groups, and later involving the community step by step. Figure 6 shows the three service elements proposed here.

\section{Highlighting on Grandma's Small Daily Life Tasks \\ Small Daily Life Tasks}

Figure 5. Service brand design.

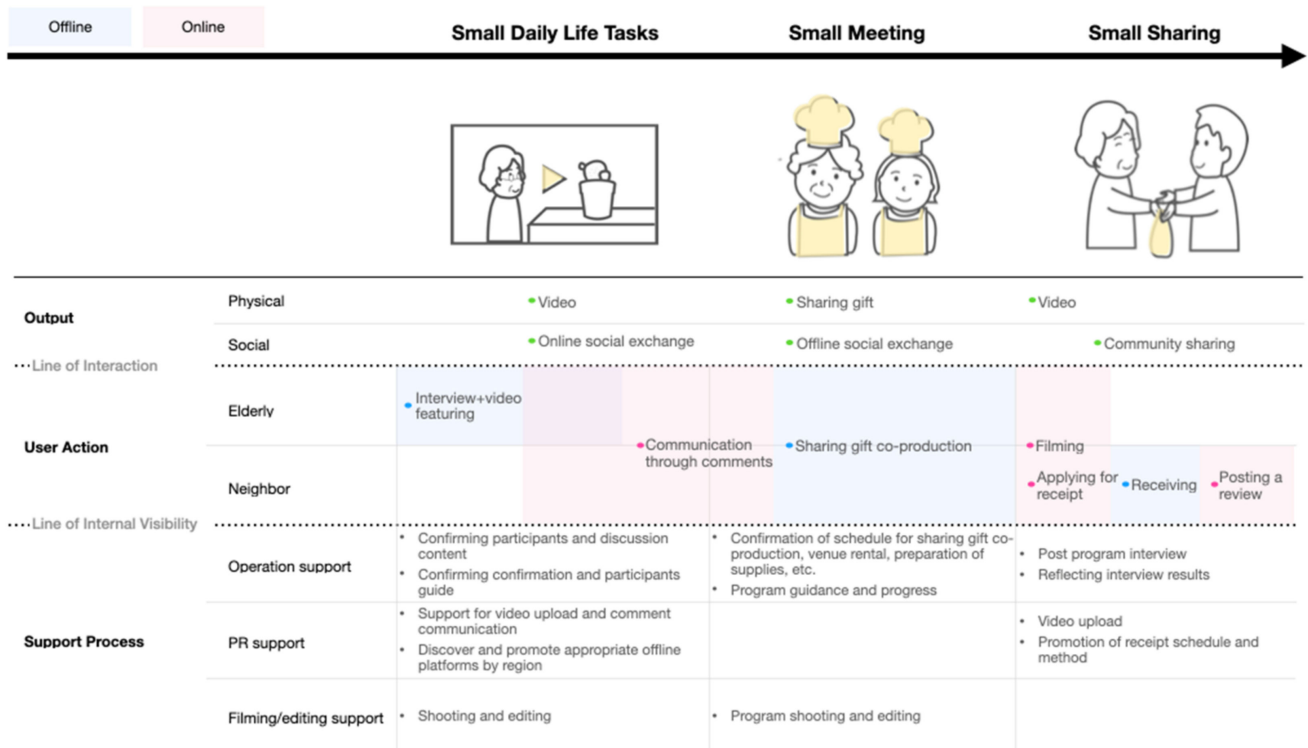

Figure 6. Service process map.

All three service processes are interconnected and extend from an individual's daily life to the community network. These processes are designed for the elderly to experience 
an improved sense of productivity and self-efficacy from their new roles and rediscover their daily enjoyment. Additionally, the meaning of home, a private space familiar to the elderly, is expanded to a communal space where the elderly meet their neighbours.

The role of service managers in the service process is as follows. First, in the "Small Daily Life Task" activity, participants were confirmed and guided, and content was discussed and confirmed. At the same time, they upload videos of small daily life tasks, support communication through comments, and discover offline platforms, such as appropriate elderly welfare centres and town hall bulletin boards for each region and used them for publicity. In the "Small Meeting" activity, the schedule of the elderly and participants was coordinated and confirmed so that the sharing gifts can be co-produced. The venue is rented and the supplies are prepared. The participants guide the program and help with the process, as well as video-recording the small meeting program, before editing it and uploading it to an online platform. In the "Small Sharing" activity, they distribute the gifts from the small meeting to the neighbours and community of the elderly ladies and promote the program through various publicity methods. Afterward, interviews are conducted with the small meeting participants, and the next small daily life program is prepared by reflecting on the reviews.

\subsection{Reflective Case Study}

Considering the COVID-19 pandemic, a case study was planned so that as few as possible researchers would visit the home of an elderly female once. To provide offline services with minimal visits, a V-log was created, focusing on the small daily tasks of the elderly, while a small meeting was conducted together during home visits by researchers. Opinions about the video and service were collected from 12 participants who watched the video with the comment text.

The elderly participant and small meeting activities for the program were selected based on the small daily life contents of older adults identified from interviews conducted to select the participants in advance. The researchers devised a small meeting program to carry out a "Making herb salt" activity that anyone can easily make at home. Figure 7 shows a specific image of the activity.
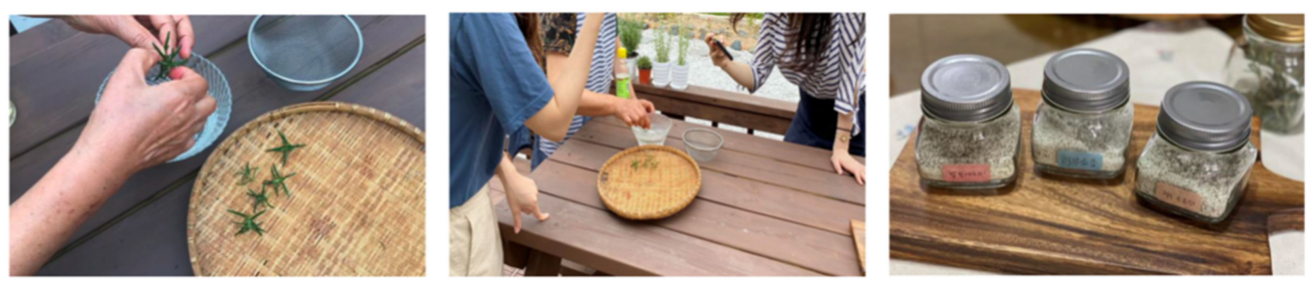

Figure 7. Case study and herb salt creation activity.

One theme that was identified in both the participating elderly and multi-generational neighbours was "positive perception of multi-generational exchange". Participants expressed their enjoyment regarding being visited by the researchers, who comprised service providers and multi-generational exchanges, in the interviews conducted after the "Small Daily Life Task" and "Small Meeting" activities. Beneficiaries expressed their "thanks" for the gifts that were shared, while video viewers gave positive reviews, stating, for example, that they had attained "purification of mind" from the grandmother's content.

The participating senior "rediscovered everyday life", with positive perceptions of the multi-generational exchanges that occurred. She recognized that her previously unrecognized daily life tasks and life knowledge could help younger generations. She reported feeling that her "everyday life was energized" while working with young people and recognized that "everyday things taken for granted can be a new learning opportunity for others", indicating that this had a positive effect on the rediscovery of familiar everyday life and her own value and efficacy. 
It was found that the service outcomes could be an effective mediator for facilitating the perception of participation needs. After seeing the service outcomes, the participating senior wanted to share, voluntarily, another talent. Additionally, many V-log viewers expressed their desire to take part in the role "if there was anything they could do to help". The three themes identified in this case study analysis-positive perception of multi-generational exchanges, rediscovery of daily life, and perception of participation needs-showed the possibility that the elderly and their (multi-generational) neighbours might be reconciled by producing "outcomes" with mediation of service. These findings suggested that the design of services to promote residential stability for the elderly should extend beyond the "provision" of services to arbitration and mediation among the elderly, their neighbours, and the surrounding communities. In other words, the elderly and their neighbours were not only beneficiaries of the service but also active participants who contributed to the community. Thus, service design should be open to support active participation. The mediation role of the service was applied to the link between the outcomes and the state's welfare support (Figure 8).

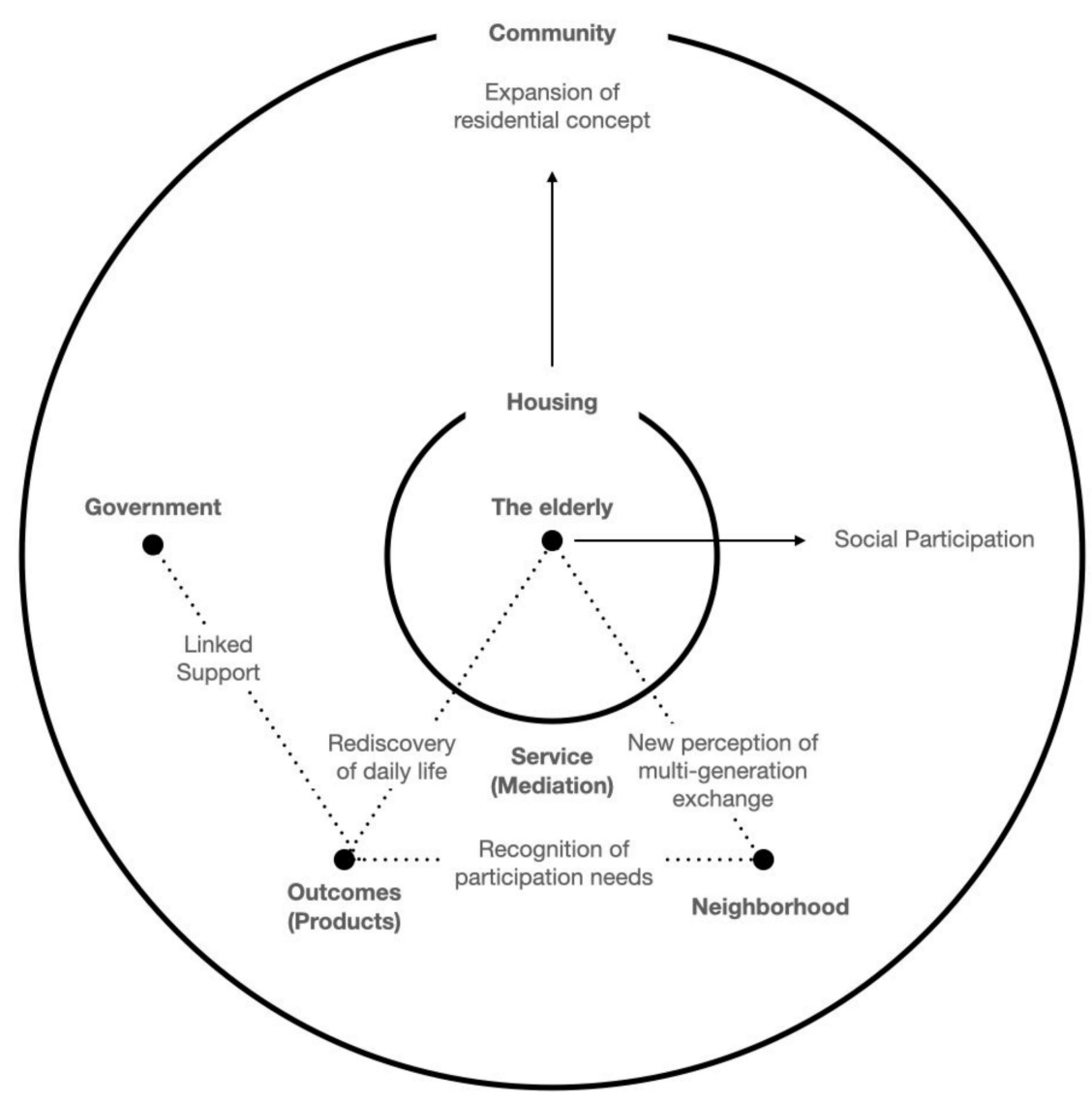

Figure 8. The conceptual living space and role of service design.

\section{Discussion}

A "residence" does not just mean a physical environment in later life but also reflects the elderly person's life-long experiences [24]. This interdisciplinary Action Research introduces a service program named "Small Daily Life", aiming for community-dwelling older adults' residential stability enhancement. When considering the presented service as research findings, this study has several implications. First, this service lowers the threshold for older adults to participate in the program because it does not require them to learn unfamiliar ones but to use their wisdom of life or hobbies. Participants may think they did nothing, but what they take will be something fruitful in a socioemotional perspective. 
This is another strength of this study, that is, positive effects on older adults' psychological well-being. The elderly can engage in social contribution activities and restore vitality and productivity through this program. It can be more potent in the COVID-19 pandemic. In addition, this study can also be helpful for community-dwelling older adults sustain independent life. Society is getting digitalized rapidly, and there is a digital divide between older adults and other generations. "Small Daily Life" is preceded both online and offline so that older people can naturally adapt to an online based situation.

Nevertheless, the number of interviewees and case study are limitations in this study. Researchers tried to compensate for these shortcomings by taking a close look at the contents of the interviews. There might be another limitation in that characteristics of some participants could be less considered than others in the service program. For example, content from Senior 2 and Care worker of in-depth interviews was used to set an inclusion criterion, rather than the main content of the service program. Through these limitations, it is necessary to consider the characteristics of the elderly such as their residence type, gender, physical decline, and so on when performing Action Research to design service programs for the elderly. Lastly, there may be a need to further discuss the identity of service mangers. Then we suggest a changeable role of service managers. Service managers can take the role of paid staff in the business model, and volunteers in the non-profit model. Overall, this service can alleviate social disconnection due to the COVID-19 pandemic and the psychological and physical aging of the elderly. The service presented here could be used as evidence for developing policy or service to support "aging in place" and lessen public expenditures for the elderly.

Author Contributions: Conceptualization, S.C., S.-A.L., M.K. and Y.L.; methodology, S.C. and H.K.L.; data collection, Y.L., M.K., S.-A.L. and S.C.; writing-original draft preparation, M.K., S.-A.L., Y.L. and S.C.; writing-review and editing, S.C. and H.-K.L.; visualization, S.C.; supervision, H.-K.L. and H.K.K. All authors have read and agreed to the published version of the manuscript.

Funding: This work was supported by the Yonsei University Research Grant of 2021.

Informed Consent Statement: Informed consent was obtained from all subjects involved in the study.

Conflicts of Interest: The authors declare no conflict of interest.

\section{References}

1. World Health Organization. Available online: https://www.who.int/news-room/fact-sheets/detail/ageing-and-health (accessed on 5 December 2021).

2. The JoonAng. Available online: https://www.joongang.co.kr/article/23568357\#home (accessed on 5 December 2021).

3. Gillsjö, C.; Schwartz-Barcott, D. A concept analysis of home and its meaning in the lives of three older adults. Int. J. Older People Nurs. 2011, 6, 4-12. [CrossRef] [PubMed]

4. Golant, S.M. Subjective housing assessments by the elderly: A critical information source for planning and program evaluation. Gerontologist 1986, 26, 122-127. [CrossRef] [PubMed]

5. Lee, Y.; Jun, E.; Victoria, P.M.; An, S. Socially intergrative planning characteristics of elderly housing in share anazawa village of Japan. KIEAE 2019, 19, 5-15. [CrossRef]

6. Bae, J. Health and social participation characteristics of korean older adults: Focusing on the older adults who participate in the senior social activities and job program of the ministry of health and welfare. Korean J. Phys. Educ. 2020, 59, 291-301. [CrossRef]

7. Mills, G.E. Action Research: A Guide for the Teacher Researcher; Prentice-Hall, Inc.: NJ, USA, 2000.

8. Buchanan, R. Wicked problems in design thinking. Des. Issues 1992, 8, 5-21. [CrossRef]

9. Manzini, E. Design, When Everybody Designs: An Introduction to Design for Social Innovation; The MIT Press: MA, USA, 2015.

10. Service Design Consulting Application Guidebook-KIDP (Korea Institute of Design Promotion). Available online: https: //www.slideshare.net/sdnight/ss-35612389 (accessed on 14 October 2021).

11. Suoheimo, M.; Vasques, R.; Rytilahti, P. Deep diving into service design problems: Visualizing the iceberg model of design problems through a literature review on the relation and role of service design with wicked problems. Des. J. 2021, 24, $231-251$. [CrossRef]

12. Design Council. Available online: https://www.designcouncil.org.uk/news-opinion/what-framework-innovation-designcouncils-evolved-double-diamond (accessed on 13 October 2021).

13. Dorst, K. The core of 'design thinking' and its application. Des. Stud. 2011, 32, 521-532. [CrossRef]

14. Dorst, K.; Cross, N. Creativity in the design process: Co-evolution of problem-solution. Des. Stud. 2001, 22, 425-437. [CrossRef] 
15. Sun, Y.; Ng, M.K.; Chao, S.T.Y. Age-friendly urbanism: Intertwining 'ageing in place' and 'place in ageing'. Town Plan. Rev. 2020, 91, 601-619. [CrossRef]

16. Boddy, C.R. Sample Size for Qualitative Research. Qual. Mark. Res. Int. J. 2016, 19, 426-432. [CrossRef]

17. Cresswell, J.W. Qualitative Inquiry and Research Design-Choosing among Five Approaches, 3rd ed.; HAKJISA: Seoul, Korea, 2019.

18. Orth, D.; Thurgood, C.; Van den Hover, E. Designing objects with meaningful associations. Int. J. Des. 2018, 12, 91-104.

19. Saldaña, J. The Coding Manual for Qualitative Researchers; Sage: LA, USA, 2009.

20. Kang, E.N.; Joo, B.H.; Lee, J.C.; Baie, H.W. A Plan to Reorganize the Senior Housing Policy in Response to Super-Aged Society; Korea Institute for Health and Social Affairs (KIHASA): Sejong, Korea, 2019.

21. Choi, W.; Jung, S.; Park, J. Housing Conditions of Elderly and Housing Policy for Aging in Place. In Proceedings of the 2017 Spring Annual Conference on Architectural Institute of Korea, Jeju, Korea, 27-28 April 2017.

22. Yoon, J.H.; Kang, M.N.; Park, C.K.; Kim, S.W.; Seo, J.K.; Jeon, H.K. A Study on Housing Service Disparity among Regions and Classes (II): Policy Measures for Improving Housing Welfare; Korea Research Institute for Human Settlements (KRIHS): Sejong, Korea, 2006; Available online: https:/ / www.krihs.re.kr/publica/reportView.do?num=000002200449\&num=000002200449 (accessed on 9 May 2020).

23. Park, H.; Nam, Y. A Study on the Characteristics of Multi-generational Center as Local Core Community Space in Germany. In Proceedings of the 2016 Fall Annual Conference on Architectural Institute of Korea, Busan, Korea, 4-6 October 2016.

24. Jung, H.; Oh, J.A. Case study of community space in the apartment complex for aging in place of the elderly. J. Cult. Prod. Des. 2016, 46, 115-127. [CrossRef] 